\title{
A content-based analysis to identify the influence of COVID-19 on sharing economy activities
}

\author{
Sajid Amit ${ }^{1}$ - Abdulla - Al Kafy ${ }^{2,3}$ (D)
}

Received: 12 December 2021/Revised: 13 January 2022/ Accepted: 15 January 2022/Published online: 3 February 2022

(C) Korean Spatial Information Society 2022

\begin{abstract}
Activities related to Sharing economy (SE) are in a vulnerable position globally due to the COVID-19 pandemic. SE businesses related to the transport and accommodation sectors are considered riskier than others, and the pandemic has only increased concerns. As such, assessing the COVID-19 pandemic's impact on the SE is crucial. This study aims to identify the influence of COVID-19 on SE activities. Journal and news articles, blog posts, YouTube videos, and printed and televised news have been considered as data sources for this study. Using content analysis, the study showcases how SE activities are adjusting to the pandemic-induced business landscape. The study examined SE status from four stakeholders' viewpoints-service providers (SPs), service receivers (SRs), SE firms, and regulatory bodies (RBs). The study's findings suggest that the pandemic-induced lockdown significantly impacted job sectors, increased health risk, anxiety, reduced safety, and income for SE firms. SPs, and SRs worldwide are facing tremendous difficulties operating their activities, frequently changing guidelines to support SPs by financial assistance and SRs by standard services
\end{abstract}

Abdulla - Al Kafy

abdulla-al.kafy@ localpathways.org;

https://abdullaalkafy.com/

Sajid Amit

sajid.amit@ulab.edu.bd

1 Center for Enterprise \& Society (CES), University of Liberal Arts Bangladesh (ULAB), Dhanmondi, Dhaka 1209, Bangladesh

2 ICLEI South Asia, Rajshahi City Corporation, Rajshahi 6200, Bangladesh

3 Department of Urban \& Regional Planning, Rajshahi University of Engineering \& Technology, Rajshahi 6203, Bangladesh during the COVID-19. This study will help respective authorities and government organizations to determine the appropriate strategies for SE firms to advance their services during critical situations.

Keywords COVID-19 - Sharing economy ·

Accommodation · Transport sector - Content analysis

\section{Introduction}

The sharing economy (SE) has provided commuters and travelers with new ways to move and more. They can use Airbnb to book a room, Uber to travel, EatWith/FoodPanda to eat food prepared by locals, and visit native attractions with Vayable [1, 2]. The COVID-19 pandemic, however, has had a significant impact on the SE. The World Health Organization (WHO) announced the spread of the novel coronavirus, an international public health crisis, on January 30, 2020. Many companies have been hit hard by subsequent restrictions on movement, but SE activities, in particular, have been impacted significantly [3-5]. However, the importance of sharing has been rising, with sectors such as healthcare, tourism, and restaurants, developing strong linkages to the SE, especially in larger cities [6-8]. COVID-19 has encouraged companies to embrace transparency in sharing policies and revising their existing ones. $[9,10]$.

The SE is also known as the collaborative economy. It works by pooling and reallocating underutilized resources, goods, time, knowledge, and skills [11]. It is expanding rapidly and favours horizontal organization structures over vertical and hierarchical ones [6]. Horizontal organizations are based on economic principles such as cost-cutting and eliminating intermediaries $[12,13]$. SE has been 
considered a promising phenomenon due to its numerous perceived economic, social, and technological benefits $[14,15]$. There are many unique SE activities, and discussion should delineate subsectors rather than lump them together [16, 17]. The SE aims to serve underutilized resources, promoting efficiency and sustainability, and this can be a weighty task for service providers (SPs) at an operational level $[9,18]$. Most SPs (such as Uber drivers and Airbnb hosts) are treated as contractors by sharing platforms, which is noteworthy because it relieves them of insurance and social benefits obligations [ $4,5,22]$. In terms of employment, it is up for debate whether Airbnb hosts, Uber Eats delivery agents, and Uber drivers should be classified as contractors, employees, or workers.

The SE has numerous benefits, and researchers have studied its explosive progress in a variety of industries, including household services (i.e., Care.com), lodging (i.e., Airbnb), and transportation (i.e., Uber) [19, 20]. Although SE studies focus primarily on Uber and Airbnb, interest has been extended to various fields. One study, for example, recognized 17 sectors and 47 subsectors for on-demand fashion, services, and food delivery, with 165 distinct actors. In general, COVID-19 has had a detrimental effect on these industries but has occasionally benefited them [19]. For example, SE meal-delivery services such as UberEats have seen a significant escalation in business. Meal sharing is also rapidly expanding due to COVID-19 $[21,22]$. However, the pandemic has forced establishments to alter their business policies in lieu of the changing environment in all instances [10]. During COVID-19, three broad phases have been identified: (a) coping with home quarantine, social distancing, remote work, and stress; b) reactions such as maintaining extra hygiene, job rejection and loss; c) long-term preparation such as finding stable, permanent jobs, establishing a new social identity and restoring consumption [13, 23-25]. Firms must have sustainable business models in order to survive, especially during the COVID-19 crisis [4, 26, 27]. The SE is viewed as a way to transform how commercial activities are done, and concerns about social embeddedness have positioned the SE as a viable option. As a result, Airbnb and Uber have appeared as serious competitors to the global hotel and taxi businesses, and these large SE firms have directly and indirectly employed millions of people worldwide $[15,19]$. Although the SE increases consumption, it can also upsurge or decline ownership depending on the type of SE activities [13]. Surprisingly, Gyodi discovered that only a minority of Airbnb listings in major European cities were truly SE [28], but re-channeled traditional offerings, like hotel rooms. Both SE and traditional hotel offerings are significantly impacted by amenities, location, services, property characteristics, rental rules, and customer reviews [29].
The credibility of various parties in SE sectors is difficult to measure from the information available on their websites. However, feedback from other guests plays an integral part in booking accommodation from SE platforms such as Airbnb [30]. According to one study, personal reputation (40\%) is strongly connected with host popularity, followed by storytelling narratives in companies profiles $(8 \%)$ [31]. In the rapidly expanding SE, racial discrimination is a massive concern. Indeed, according to a recent study of 1801 Airbnb hosts, individuals with African-American-sounding names were $19 \%$ less likely to be acknowledged as visitors than those with white-sounding names $[12,32]$. Despite the growing importance of SE firms as a form of alternative consumption, research is still in its early stages [33]. However, SE is a growing research topic in various disciplines, and the media has reported on $\mathrm{SR}, \mathrm{SP}$, and SE firm problems triggered by the pandemic [34]. The SE is now under serious threat, but there is a significant shortage of academic investigations into the effects of COVID-19 on SE [11].

SE firms that once appeared profitable are now losing value, raising the concern of how SE can recover. Unfortunately, despite its substantial economic influence on many countries, the SE is often ignored in crisis stimulus packages. An investigation needs to be taken to identify how COVID-19 is impacting different sectors of business, especially the highly affected internationally operating SE firms such as ridesharing services (Uber and Lyft), apartment/house-sharing platforms (Airbnb and Vrbo) and meal-delivery services (UberEats). In addition, the difficulties faced by SPs (Uber drivers and Airbnb hosts) and service receivers (SRs) of SE firms, along with the measures/strategies taken by regulatory bodies of these firms to combat the COVID-19 impacts, need to be investigated. Therefore, this research aims to answer two questions in the global context for the first time on the effects of COVID-19 on regulatory bodies of SE companies, their SPs, SRs. In addition, the dealing strategies made by the regulatory bodies of SE firms, their associated SPs, and SRs regarding the consequences of COVID-19 will also be investigated in this study.

A content-based analysis of selected documents was performed to uncover the answers. Various factors such as behavioral attitudes of SRs and SPs, the anxiety of SPs and regulatory bodies due to the reduction in income, job loss of the SPs, the impact of event cancellation on tourism and apartment haring platforms, health risk and safety of the SPs and SRs, possible overcoming policies need to be adopted by the regulatory bodies of SE firms have been explored to understand how the pandemic has impacted SE sectors [35]. A literature review has been performed in the next section, Sect. 2. The research methods are then explained in Sect. 3, including data, collection, and 
analysis. The study's findings are presented in Sect. 4, and the final section discusses implications and possible future research directions.

\section{Methods}

\subsection{Study area and research setting}

This research has a universal setting, so it is not limited to a specific county. It considers COVID-19-related events, occurrences, and decisions in the global SE sector. This is an empirical study with a qualitative approach. This investigation emphasizes capturing SE status during the pandemic using secondary data sources, which are commonly utilized for high-quality research $[6,36]$. In fact, secondary data is more suitable for this study, as data on first hand would struggle to provide a global understanding of the impact of COVID-19 on SE. Secondary data is widely used in a variety of fields because of its several advantages in academic studies, especially in microfinance [37], strategic planning [17], sustainable tourism development and management [38] and hotel performance management [39]. It depicts real decision-makers precise decisions, which were gathered in a less obstructive manner and were not influenced by self-reporting biases. As such, it is possible to avoid biases associated with the key informant sampling approach. Recent studies based on online comments on a newspaper article about SE vividly illustrate the value of such data in research $[16,30]$.

\subsection{Datasets}

The primary data sources are journal, newspaper, and popular press articles, blog posts, and video clips, which were gathered through a comprehensive search. Keywords shown in Table 1 were used when searching for relevant articles. Only documents in English that clearly explain the SE in connection to COVID-19 were included. The searches were carried out during February and March 2021. When an appropriate and relevant document was found, its title and a web link were added to the spreadsheet. Collected documents listed in the spreadsheet were sorted after the collection process to see if any has been recorded twice. Several documents were found to have duplicate information and were removed from the list. The authors do not claim to have covered all of the related documents on the internet but believe that the list is inclusive enough to deliver an insightful academic contribution to COVID-19 impact on the SE. The final set of documents included 221 written documents and 32 videos. The next section of this article carefully examines all the collected documents, and the main points from the documents have been reported.

\subsection{Data analysis}

All documents were saved in a temporary folder after being downloaded as PDFs. These were subsequently combined into a single PDF document of 1135 pages. Content analysis (CA) was performed to organize diverse data, including coding information, into different categories [40, 41]. CA can contribute a new depth of understanding for a phenomenon that has received limited attention [42]. The combined document was uploaded to Qualitative Data Analysis (QDA) Miner Lite, an effective qualitative data analysis program. A free basic version was used, which is sufficient for coding and data analysis purposes. Various preselected codes and additional codes were used to obtain information through open coding. The pre-selected codes included job loss, salary cut, anxiety, booking and travel cancellation, hygiene, social distancing, and health safety. However, before completing the coding work, additional codes were added, such as difficulties faced by SE firms, strategies to overcome the difficulties, positive/adverse outcomes during and post COVID-19 stage, and so on. Each document was read line by line and coded accordingly. After completing this iterative coding process, several codes were merged into one to reduce the number of coding groups to a more manageable level. After completing the coding process, the coded texts were extracted into Excel files and synthesized the data into four categories: SE platforms, SR, SP and rules and regulatory

Table 1 Data sources used for the study

\begin{tabular}{lcll}
\hline Data source type & No. of documents & Collection sites & Searching keyword \\
\hline Journal articles & 57 & Google Scholar & $\begin{array}{c}\text { SE and COVID-19, Uber and COVID -19, SE and coronavirus, } \\
\text { AirBnb and COVID-19, AirBnb and coronavirus }\end{array}$ \\
Newspaper articles & 134 & Google Search & \\
Reports & 24 & Google Search & \\
Blogs & 21 & Google Search & \\
Video clips & 32 & Facebook and Youtube & \\
\hline
\end{tabular}


bodies. In the following section, the results of this study are thematically described.

\section{Results}

The COVID-19 pandemic has affected SE firms, SRs, SPs, and regulatory bodies. This section thematically describes the findings collected from CA of selected documents, summarized in Tables 2, 3, 4 and 5

\subsection{Health risk, safety, and social distancing}

Various social distancing measures, such as $1 \mathrm{~m}-, 1.5 \mathrm{~m}-$ and $2 \mathrm{~m}$-distancing, and so on, can be found worldwide. Regardless, many SPs and recipients can't practically maintain social distancing and face significant problems (Table 3). Drivers, for example, are unable to maintain social distance while in a car with passengers. According to Yaseen Asleem, president of the "United Private Hire Drivers Association", "It is impossible for drivers to maintain a social distance of $2 \mathrm{~m}$, but it is a mess because there are no clear guidelines." A passenger brought Uber to a hospital and was found to be COVID-positive. Uber, in turn, suspended the driver. Similar stories can be told for thousands of drivers worldwide. The local ridesharing platform Didi installed protective plastic sheets in China's cars to isolate drivers and passengers. Meanwhile, Uber introduced features in its app that allowed users to examine if drivers are wearing facemasks before embarking on a trip. It also directed passengers to sit in the backseat and to wear masks.

Both SE providers and customers are concerned about hygiene. Drivers are instructed to disinfect their vehicles regularly, mainly surfaces where travelers may come into contact, cover any coughs or sneezes, wash their hands, and stay at home if they are sick (Table 2). Ridesharing customers encourage riders to be more careful because they meet plenty of other people. Airbnb has also established hosting cleaning protocols, including a 24-h gap between guests staying in accommodation, thanks to a collaboration with a former US surgeon general on hygiene training. Additionally, the company has itemized a collection of products for hosts to use to clean their properties. The company issued a press release that stated, "We believe enrolling in our enhanced cleaning initiative, with support and resources from $u s$, demonstrates a genuine commitment to cleanliness and sanitation for guests".

Passengers unknown to each other can no longer travel together via Lyft Line and Uber Pool options. "Individual drivers are responsible for cleaning their cars" says the founder and CEO of The Rideshare Guy website. Riders, must deal with uncertainty in regards to how clean a particular car may be. While some drivers diligently maintain cleanliness, others are less concerned. Furthermore, some drivers have difficulty obtaining the necessary cleaning material and shielding equipment in their communities.

Even though hotels are more dependable in terms of cleanliness, elevators and lobbies may cause guests concern because they are frequently used throughout the day. Some argue that riders should make sure their car air vents are fresh air rather than recirculation and that drivers should not assist passengers in loading and unloading luggage. Others argue that home-sharing services should be controlled similarly to real estate organizations and other types of accommodation services.

Uber is also assisting drivers with delivery and extra services, but this is not entirely safe, even though it is likely safer than transporting passengers. For example, delivery drivers must enter restaurants to collect orders, putting them at risk of infection regularly. Uber also requires all drivers and riders to wear facemasks and recommends switching gloves between riders. This means that if a driver makes 20 rides or deliveries per day, he will require 20 sets of gloves. Considering these above points, social distancing, hygiene, and safety continue to be major concerns in the SE.

\subsection{Backlash of SP, SR, and SE firms}

SE services have faced a backlash from several sources. Critics claim that Airbnb has distorted the rental market by imposing stricter regulation, and it has been blamed for worsening housing scarcities. Airbnb defends itself by claiming that it generates income that benefits local communities. So far, it seems that SE platforms have been successful in preventing regulation. However, the COVID19 pandemic led to further criticism because the SE workers were given government support to pay taxes to help workers when they could not work. In the United States, upcoming new unemployment programs aim to compel these businesses to contribute so that drivers can receive benefits more quickly. According to one San Francisco host, Airbnb is forcing SR to bear the majority of the cost of compensations without taking any effective decision to provide free travel insurance using the host's expense (Table 4). According to reports, Silicon Valley companies such as Uber and Airbnb are lobbying the US government to ensure that their independent contractors and sole proprietors receive unemployment benefits. Besides, Uber's CEO has contacted ten members of Congress. In a similar vein, three Airbnb co-founders met with more than a dozen members of Congress. Members of Congress received a presentation about the scooter industry from a lobbying firm representing Lime and Bird. These 
Table 2 Impacts. Overcoming policies and possible outcomes of COVID-19 on SE services

\begin{tabular}{|c|c|}
\hline Sectors & COVID-19 impacts on SE services \\
\hline Behavioral Attitudes/Backlash & $\begin{array}{l}\text { - Criticism for not supportive to service receivers and providers } \\
\text { - Furious behaviour from investors } \\
\text { - SE firms ignore the SPs } \\
\text { - SE firms and SP ignore the SR } \\
\text { - Not helping the SR } \\
\text { - Not providing clear procedures to the SP and receivers } \\
\text { - Significant delay took place in delivering any product } \\
\text { - Not maintaining social distancing according to the guidelines }\end{array}$ \\
\hline Anxiety & $\begin{array}{l}\text { - Significant loss of SRs } \\
\text { - Negative media coverage } \\
\text { - Afraid of losing company reputation } \\
\text { - Not sure about the continuation of the pandemic situation } \\
\text { - Devaluation of the company } \\
\text { - Unexpected demand from SRs and provider } \\
\text { - Scared of shutting down business activities } \\
\text { - Afraid of their own health }\end{array}$ \\
\hline Reduction in income & $\begin{array}{l}\text { - Irregularity of monthly salary, } \\
\text { - Receiving half salary from the actual salary } \\
\text { - Reduction of salary for employees } \\
\text { - Allowance and bonus are cancelled } \\
\text { - Promotions of employees are stoped } \\
\text { - Festival bonus/allowance reduces or stopped in some cases }\end{array}$ \\
\hline Job loss & $\begin{array}{l}\text { - Termination of project-based employees } \\
\text { - Extra financial support not provided to employees } \\
\text { - Major redundancy }\end{array}$ \\
\hline Event cancellation & $\begin{array}{l}\text { - Travel and hotel booking cancellations } \\
\text { - Corporate tour event cancellation } \\
\text { - Business trips cancellation } \\
\text { - No bookings }\end{array}$ \\
\hline Health risk and safety & $\begin{array}{l}\text { - Concern about the health risk of employees, SP, and receivers } \\
\text { - Risk of being infected for SR, providers, and employees } \\
\text { - Absence of proper regularity measures in hygiene from SPs and receiver ends }\end{array}$ \\
\hline Overcoming policies & $\begin{array}{l}\text { - Need to increase flexibility for employees by providing work from home/office } \\
\text { - Secure additional subsidies to support SPs and compensate the customer } \\
\text { - Make health insurance for employees and SP } \\
\text { - Stop providing service during the pandemic } \\
\text { - Stop or limit services in high infected areas } \\
\text { - By Seeking financial help from the state government } \\
\text { - Awareness building for all } \\
\text { - Helping SP to maintain social distancing by providing items }\end{array}$ \\
\hline
\end{tabular}


Table 2 continued

\begin{tabular}{ll}
\hline Sectors & COVID-19 impacts on SE services \\
\hline Possible outcomes & - Job risk \\
& - Income reduction \\
& - Monitory loss for SE sectors \\
& - Facing problems for services receivers \\
& - Investor concern \\
& - Company devaluation \\
& - Personal anxiety \\
& - Fall of the economy for different cities \\
& - Mental stress \\
& - Deprived of holiday \\
& - Tough to manage the SE sectors \\
& - Travel disruption \\
& - Search for long-term tenants \\
& - Experience cost of assets without earning \\
& - Business and financial loss \\
& $\bullet$ Unhappy SR and provider \\
\hline
\end{tabular}

Table 3 Impacts. Overcoming policies and possible outcomes of COVID-19 on SP services

\begin{tabular}{|c|c|}
\hline Sectors & COVID-19 impacts on SP services \\
\hline Behavioral Attitudes/Backlash & $\begin{array}{l}\text { - Not maintain the health rules and social distancing guidelines } \\
\text { - No provision for canceled events } \\
\text { - Not helping the customers properly }\end{array}$ \\
\hline Anxiety & $\begin{array}{l}\text { - Income reduction } \\
\text { - Afraid of losing the job } \\
\text { - Scared of infected by COVID-19 } \\
\text { - Tensed about the pandemic situation } \\
\text { - Unpredictable future }\end{array}$ \\
\hline Reduction in income & $\begin{array}{l}\text { - No opportunities to serve the receivers as no income } \\
\text { - Allowance and bonus are cancelled }\end{array}$ \\
\hline Job loss & $\begin{array}{l}\text { - Bound to stop working by platforms } \\
\text { - No new bookings } \\
\text { - Booking cancellations }\end{array}$ \\
\hline Event cancellation & $\begin{array}{l}\text { - Booking cancellations } \\
\text { - Account suspension } \\
\text { - No new bookings }\end{array}$ \\
\hline Health risk and safety & $\begin{array}{l}\text { - Insecure about their own health } \\
\text { - Insecure of the safety of the customers }\end{array}$ \\
\hline Overcoming Policies & $\begin{array}{l}\text { - Stop providing service } \\
\text { - Take extra care in cleaning hygiene and safety } \\
\text { - Try to reassure customers } \\
\text { - Refund policy }\end{array}$ \\
\hline Possible outcomes & $\begin{array}{l}\text { - Personal anxiety } \\
\text { - Search for long-term tenants } \\
\text { - Business and monetary loss } \\
\text { - Experience cost of resources without earing } \\
\text { - Life-changing choices about careers }\end{array}$ \\
\hline
\end{tabular}


Table 4 Impacts. Overcoming policies and possible outcomes of COVID-19 on SR services

\begin{tabular}{|c|c|}
\hline Sectors & COVID-19 impacts on SR services \\
\hline Behavioral Attitudes/Backlash & $\begin{array}{l}\text { - Not respecting agreement with SPs } \\
\text { - Cancelled bookings } \\
\text { - Not maintain social isolation and health guidelines }\end{array}$ \\
\hline Anxiety & $\begin{array}{l}\text { - Stop using SE service } \\
\text { - Unpredictable future } \\
\text { - Scared of COVID-19 effect } \\
\text { - Difficulty to get positive COVID-19 tests } \\
\text { - Insecurity about what is happening }\end{array}$ \\
\hline Reduction in income & - Consumers cannot afford various SE facilities due to limited or no income \\
\hline Job loss & $\begin{array}{l}\text { - No or condensed income due to jobless } \\
\text { - No need for SE service }\end{array}$ \\
\hline Event cancellation & $\begin{array}{l}\text { - Booking cancellations } \\
\text { - No option to book service } \\
\text { - Account postponement }\end{array}$ \\
\hline Health risk and safety & $\begin{array}{l}\text { - Consumers choose not to use SE firms } \\
\text { - Customers can not maintain the safety precautions due to the pandemic } \\
\text { - Customers can not maintain the health rules when using SE firms services }\end{array}$ \\
\hline Overcoming Policies & $\begin{array}{l}\text { - Stop using services from SE firms } \\
\text { - Maintain health rules and social distance } \\
\text { - Should be concern about own health } \\
\text { - Take extra care in cleaning, hygiene, and safety }\end{array}$ \\
\hline Possible outcomes & $\begin{array}{l}\text { - Mental stress } \\
\text { - Travel disruption } \\
\text { - Deprived holiday } \\
\text { - Personal financial loss } \\
\text { - Using SE firms as little as possible }\end{array}$ \\
\hline
\end{tabular}

businesses have been widely chastised for lobbying against worker rights while avoiding paying taxes.

Despite the fact that many of these businesses (Uber, Airbnb etc.) have much cash on hand, they do not intend to provide sick pay to their employees [6]. Such benefits, for example, could have cost as little as 2.7 cents per hour of paid work [14, 27]. Uber has yet to decide whether or not to suspend its services in order to prevent the spread of coronavirus, and many people have criticized the company's inaction [19]. Some drivers in the United States and the United Kingdom have died as a result of working during the pandemic. On the other hand, Airbnb eventually refunded and assisted hosts in some way [32]. Other competing platforms, like Vrbo, faced customer blowback because they refuse to provide reimbursement. SE companies are under immense pressure to pay benefits to SPs, like paid sick leave. Uber and Lyft are both facing lawsuits in California alleging that they improperly classified their drivers as independent contractors [43]. Airbnb charges guests $3 \%$ of the cost of hosting in addition to a variable service fee, whereas Uber charges drivers a $25 \%$ commission on trip costs $[19,30,32]$. This is widely regarded as outrageous, particularly in light of the COVID-19 crisis.

\subsection{Salary cuts and job losses}

Uber drivers have seen a dip in income and are fearful of the extent of financial damage the pandemic will cause. According to the latest report, SE sector has produced 6.23 million jobs in the United States alone, with 78 million amenity providers and 800 million people involved. Another recent report indicates $53 \%$ of 871 surveyed drivers are anxious about their incomes, which have decreased by $67 \%$ in the pandemic [6]. Many people have also lost their jobs in the SE sector worldwide, with Uber and Airbnb reducing their staff by 17\% (3700 personnel) and 25\% (1900 personnel), respectively in May 2020. Laid-off Airbnb workers in the United States were given 14 weeks of base pay plus one additional week for each year they worked for the company. It also created a public 
Table 5 Impacts. Overcoming policies and possible outcomes of COVID-19 on service regulatory agencies

\begin{tabular}{ll}
\hline Sectors & COVID-19 impacts on Regulatory Agencies services \\
\hline Behavioral Attitudes/Backlash & - Frequently altering guidelines \\
& - Lack of provision from people during COVID-19 \\
& - People not maintaining safety measures, which creates problems in taking any action \\
& - Extraordinary financial sustenance for people \\
Anxiety & - Impulsive future \\
& - Inadequate testing centres \\
Reduction in income & - Need to deliver additional financial support to citizen \\
Job loss & - Many jobless citizens \\
Event cancellation & - Change existing regulations \\
Health risk and safety & - Diverse safety measures in different circumstances \\
& - Difficult safety instructions \\
Overcoming Policies & - Ensure health safety for providers and receivers \\
& - Financial support for service receivers and providers \\
& - Actions to regulate SE service \\
& - Need skilled medical manpower \\
Possible outcomes & - Need more treatment facilities with adequate testing centers \\
& - Challenging to manage the SE sectors \\
& • Compensating citizens who have little or low income
\end{tabular}

recruitment list, the Talent Directory, to help these employees find new jobs. Cost-cutting measures hit employees in the marketing and design departments the hardest. Additionally, the Airbnb founders chose not to take a salary for six months, while top executives took a $50 \%$ pay cut. There are 22 in-house secretaries and 80 members of the design team who are no longer employed. Lyft, a competitor to Uber in the United States, has laid off 982 workers, or $17 \%$ of its workforce in May 2020, and cut base salaries of top executives. Furthermore, the remaining employees will only receive $70 \%$ of their salary during the crisis period. Engineers at Lyft are well compensated, with an average salary of $\$ 263,000$ per year. Lime, a scootersharing startup, also laid off $13 \%$ of its workforce ( 83 personnel) in addition to a 14\% decrease in February 2020. Similarly, in March 2020, Bird (400 employees) laid off $30 \%$ of its overall workforce.

\subsection{Anxiety}

Customers in SE had to cancel their Airbnb reservations, and the majority of individuals stopped using Uber. As a result, these services struggled to retain consumers, SPs, and investors. As a result, anxiety has had a cascading influence across the different levels of SE activity. Customers and SPs who were dissatisfied vented on social media. For example, customers complained about having to demonstrate that they couldn't travel due to national security protocols to get a refund from the platforms. The number of visitors residing in SE properties dropped significantly, and those who showed up were worried about the COVID-19. Some SE facilities came to a halt in many cities, and customers found it difficult to travel, particularly in emergencies. Instead of refunding expenses, SE services offered credit for upcoming usage, despite customers demanding refunds. SPs were also very worried. Many hosts manage accommodations as a full-time job and have many properties rented from landlords, putting them in extremely vulnerable situations. According to a host in Malaysia, the tenancy rate of SE properties was zero in various cities: "Pre-COVID-19, it was rented 10 out of 30 days at RM200 (USD45) a night. Now, zero."

Another host expressed her concern, saying, "Since the commencement of the summer of 2018, it has been fully booked via Airbnb, almost entirely by foreign tourists, but 100 percent of the reservations for April, May, and June have been cancelled." Some hosts had depended on Airbnb income to make mortgage payments, but their earnings had dropped to zero as their mortgage debt grew. A host's statement sums it up perfectly: "I now have two mortgages, no income, and I'm not sure when I'll be able to start doing Airbnb again."

Diana Jeong, an Airbnb Superhost, quit her job five years ago to become a full-time host because she was expecting a child this spring. She now has no source of income and believes Airbnb treated its hosts unfairly 
during the COVID-19 pandemic. Many hosts also believe that visitors cancelled their reservations in order to take a full refund, even if their motives were unrelated to the pandemic, and that Airbnb did not consult with them in the decision-making procedure. For instance, visitors may have discovered a lower-cost option while getting a full refund for an existing reservation. One South Philadelphia Airbnb host resigned from his job as a college professor to become an Airbnb host, and he purchased a neighbor's property for the same purpose. He currently has no source of income, and his prospects are bleak. Another host with 50 apartment units decided to close her shop due to the COVID-19. In April 2020, more than 4,100 hosts registered their property on the Minpaku SE platform, which comprises 25,000 properties throughout Japan. Some hosts are senior citizens who have a limited regular income and rent out rooms in their homes to supplement their income; however, long-term rentals are not an option for them. Some hosts believe that visitors are mistreating the system by demanding refunds after staying in their properties. Some of them are considering legal action in response to this type of malpractice.

Meanwhile, some SE firms have suspended accounts of drivers due to public health concerns. Passengers infected with COVID-19 can also infect drivers, which is why many drivers have stopped working. On the other hand, some drivers are in dire straits because they do not have access to unemployment benefits and thus have no option but to drive to support their families. A heartbreaking example comes from London, where a driver passed away after being exposed to repetitive coughing from a female traveler-the late healthy Uber driver's final message to his family being: "I am really scared. Pray for me."

Many single mothers are SE drivers, and their anguish is a serious problem. "Getting sick would affect my ability to pay rent and feed my child," Tina Raveneau, a single mother with a son, explained. App companies must at least guarantee that if I pick up an infected rider and need to return home to quarantine myself, my bills will be paid." In the United States, $22 \%$ of Uber drivers are African Americans, and are a vulnerable group. Driver Jerome Gage, explains why he drives despite the pandemic: "Yeah, I'm working because people need us and they are unwilling to rely on public transportation." He believes that the request for trips has decreased significantly, and he spends his time waiting for customers, passing the time watching YouTube and Netflix.

According to another report, Uber is the prime source of income for numerous black drivers, and they do not have enough money to stop working and support their families. On The Rideshare Guy blog, one driver stated, "Sickness is not an option for me because not working is not an option. If I get sick, I'll have to keep working or I'll lose my ability to exist; it's more than just money." Despite the fact that Uber offered compensation to drivers affected by the COVID-19, many drivers do not know where to obtain the necessary documentation. Furthermore, because of long lines in many cities, getting a COVID-19 test can be difficult, as a driver named Chen expresses: "The other drivers I talked to don't understand how to get tested and how to get sick pay, and the concern is they don't know who to go to. It is not made clear by Uber." Each driver has his or her own set of issues. For example, one diabetic driver stopped driving as a precaution, whereas another driver couldn't because he needed to meet a minimum number of rides in order to keep the car he rented from a company. As a result, SE SPs are struggling to balance life and work-to stay healthy while earning a living.

According to Airbnb, closing services in certain cities is a public health decision, as declared by the World Health Organization (Table 5). Because of the rapid onset of the coronavirus crisis, most businesses failed to communicate effectively with their employees, SPs, and other external shareholders. Airbnb, for instance, had to express regret to its SPs for miscommunication, as evidenced by the message from the Airbnb CEO: "I deeply regret the way we communicated this decision, and I am sorry that we did not consult you as partners should. We've heard from you, and we're sorry if we let you down. You have the right to expect better from us." However, requiring documentation to demonstrate that an individual is unable to travel due to the COVID-19 is unrealistic, as each country, state or city may have its own set of regulations. The platform's perplexing messaging increased the anxiety of SPs and customers. One Airbnb guest, for example, received the following message: "Your cancellation request was approved, and you will receive a full refund of $\$ 0.00$." Investors are also putting pressure on platforms, and Uber claims to have $\$ 10$ billion in unrestricted cash on hand to appease them.

\subsection{Booking cancellation}

Booking cancellations occurred all over the world. Between February 3 and April 13 2020, according to AirDNA, an association that tracks Airbnb bookings, there was a 53\% drop in US bookings. Meanwhile, a Newsy poll found that after COVID-19, 27\% of people are less likely to use car-sharing. In some cities, Airbnb bookings were also prohibited. Some hosts and customers were perplexed by financial issues such as termination fees and commissions. Weekly app downloads for China's Didi and France's BlaBlaCar fell the most, by $75 \%$ and $65 \%$, respectively, between January 2019 and March 2020. From 40,000 in the first week of January 2020, bookings in Beijing fell to 1655 in March's first week. Many hosts were affected by Airbnb cancellations, and they were unsure 
what would happen to the commissions they had received from bookings. Airbnb set aside $\$ 250$ million to support hosts for missed and cancelled bookings after receiving backlash from various quarters, as reported by several media channels, including CNBC. Guests can cancel their bookings for free under Airbnb's Extenuating Circumstances Policy. It has also established a $\$ 10$ million "Superhost Relief Fund" to assist Superhosts who are unable to pay their rents or mortgages. In addition, Airbnb has guaranteed to refund cancellations for bookings made between March 14 and May 31, 2020. However, no ome who had made a reservation for July or later received a refund. For example, Michael Carino's July reservation did not fall within the refund period, so the host will follow the standard cancellation policy. He's still waiting for a refund on his booking. "This limited time frame is not fair to restrict," said Carino. Airbnb is allowing guests worldwide to cancel reservations and receive a full refund, but the process for doing so was initially unclear. Some hosts believed that refunds should not be given to customers, as one host stated: "I don't understand people whining about how they couldn't get their money back for their vacation. If you want to be flexible, stay in a hotel. Almost all hotels will allow you to cancel if you do so within two days. You are also welcome to purchase travel insurance." Some hosts have experienced $100 \%$ cancellations for properties that are usually fully booked.

\subsection{Overcoming strategies}

The COVID-19 has caused companies and SPs to reconsider their services, and many have implemented strategies to lessen COVID-19's effects. Accommodation providers are thinking about finding long-term occupants and concentrating on national rather than international guests. For example, one host who manages 60 Airbnb apartments stated, "Prior to the crisis, our clients were $90 \%$ to $95 \%$ foreigners. We only had a few French people book our apartments." Airbnb has stated that it will prioritize longterm stays, and the mandate for this has recently increased. By reducing its reliance on hotel-style accommodations, it hopes to refocus its core business. On the other hand, Uber believes that after COVID-19, there will be a surge in travel movement. People are increasingly looking for vacation destinations closer to home, as Airbnb CEO Chesky stated in a note to employees: "People will want options that are closer to home, safer, and more affordable." Controlling safety guidelines and protocols to reduce coronavirus transmission will be difficult for SE firms. Airbnb postponed its planned IPO in favour of a billion-dollar debt deal from two equity firms and a billiondollar loan from institutional investors to address the coronavirus crisis.
Uber plans to provide drivers and passengers with a travel insurance scheme. It has established an internal team to work with local and domestic health officials to provide their contractors with healthcare facilities. Travel insurance appears to be an essential consideration, especially in this time of crisis, as one customer states: "It's because Airbnb can't be bothered to offer travel insurance (even via a third party). They simply make it sound as if their policies make it unnecessary (which isn't true)." Many customers might purchase separate travel insurance to safeguard themselves from unanticipated delays.

For the first time, stimulus packages have allowed states to provide unemployment insurance to SPs. In the United States, unemployment benefits, combined with a $\$ 600$ weekly supplement from the federal government, have relieved many drivers' stress. But many SPs had to wait a long time because many countries required their regulations, processes, and portals to be updated. Airbnb has provided free stays in Airbnb accommodations to frontline workers such as doctors, nurses, and technicians in order to support efforts to combat the COVID-19 pandemic. Thanks to new legislation, small business grants and loans are now available to hosts in the United States. However, according to one driver in the United States, people view government assistance as a last resort because they want to work. However, during this crisis, individuals have been forced to apply for government aid. According to Airbnb, many visitors have expressed gratitude to hosts for their flexibility and have conveyed a willingness to support them financially. Airbnb is launching a platform for guests to communicate with their hosts and make financial contributions. According to one expert, Airbnb consumers are very forgiving because they like the company, and the company benefits from this perception.

\subsection{Possible outcomes of the COVID -19 pandemic}

Many people are relieved to see home-sharing come to an end, and some believe that residents in popular regions will have a better quality of life as a result. There is a link between home-sharing's upsurge and long-term residents' departure from neighborhoods, particularly in tourist-heavy metropolises. Increased long-term occupancy results in less noise and more locally-oriented businesses and amenities. There has recently been an increase in advertisements for long-term residents in city centres and tourist areas. Many of these include neatly bent towels and set kitchen tables that were earlier used only for SE purposes, and long-term tenants can now rent at a lower price. Some argue that these SE platforms drove long-term tenants out of neighborhoods by manipulating housing for revenue through short-term rentals. 
Because of hygiene standards, some specialists believe that people may now prefer traditional hotels to homesharing. "They simply can't assurance a deep clean on a host-to-host basis after every guest," one expert says. Other experts argue that, even after the COVID-19 crisis, individuals will prefer service apartments over shared accommodations and hotels for cleanliness and social distancing. Because hotels are major taxpayers, many cities may see a drop in revenue. More long-term tenants are renting at a lower price in big cities and tourist areas, but some experts have confidence that sharing services will bounce back and eventually flourish again. However, some large platforms, such as Uber and Airbnb, will find it more difficult to go public now. Remote work is becoming the norm and online meetings and collaborative work platforms are increasing. Local governments will also pursue new short-term letting strategies.

The SE has a significant impact on national economies. On the other hand, SPs without a financial safety net are in jeopardy. Platforms such as Airbnb and Uber face a push to evolve into more responsible businesses by improving health insurance, travel insurance, SPs' employment status, and collaboration with local governments. Airbnb's market capital was valued at \$53-65 billion in 2018, more than Marriot ( $\$ 46$ billion), the world's leading hotel enterprise. Airbnb has a market capitalization of $\$ 26$ billion. The COVID-19 pandemic may also result in a $9.7 \%$ drop in global GDP. Car sales have plummeted dramatically, and companies are now selling vehicles online.

\section{Discussion}

This study provides an inclusive picture of the SE during the COVID-19 pandemic. Even though COVID-19 has impacted all sectors, it has been particularly harsh on SE sectors, whose SPs are among the most vulnerable. The once-giant SE firms have been devalued substantially, and some may have to close their operations or merge with other companies. Customers have also lost money and missed out on travel opportunities, but their exposure is less than SPs. Provided next are some theoretical and practical implications of this study.

\subsection{Theoretical implications}

This study has a number of theoretical implications since it adds to our understanding of the COVID-19 in the SE literature, as there have been no previous studies on the subject. SE is a vital part of millions of people's lives worldwide, and the COVID-19 had a significant impact on SE activities. The study contributes to the discussion of COVID-19 impacts on SE activities and the broader business and management fields. The findings reveal the state of SE during the COVID-19 crisis. Many SE firms have begun hygiene and safety training programs. On the other hand, we lack knowledge in terms of hygiene and safety. Despite the fact that there have been studies on crisis management, this study focuses on SE accomplishments so that scholars can learn more about SE. Sharing platforms have come under fire from various quarters, despite the growing importance of academic research.

To mitigate the negative impact of the COVID-19 on SE, insurance policies must be developed, SPs must be treated more like employees, and safety measures must be implemented to ensure SE does not face repercussions for their shady business practices. It is critical to establish proper communication channels between various parties, and the SE firms are primarily responsible for this. The COVID-19's long-term consequences are unknown because various things are fluctuating in the SE sector due to the pandemic.

\subsection{Practical implecations}

Many SE firms have been heavily criticized for various reasons, and COVID-19 has heightened the scrutiny, prompting the SE firms to reconsider their business strategies. They must have policies in place to safeguard their key stakeholders. They are, however, expected to maintain their dominance in their respective industries. Even if clients are dissatisfied with the platforms, they do not have any better options for future travel for the time being. Many people will continue to use sharing services in the future. Many platforms grew quickly and became highly profitable, and their SPs easily earned more than they anticipated. However, they did not take into account issues that other businesses and SPs must consider, such as taxation, safety, risk, hygiene, and so on. Balancing health and livelihood is a major concern for SPs [44]. They cannot support their families if they do not have any income source, but working during the COVID-19 pandemic may put them and their families in danger.

It is clear that city officials will impose strict rules on SE services in order to increase tax revenues. Furthermore, issues of safety and hygiene will become more critical in the future. SPs may require cleaning demonstrations training to persuade potential customers of their commitment to hygiene. COVID-19 makes insurance imperative, in particular for drivers and passengers. Furthermore, governments may compel sharing platforms to treat their contractors (SPs) as employees in order to avoid financial hardship during a crisis.

Many drivers have long gaps between trips and spend their free time doing things like watching movies and YouTube videos. It would be exciting to brainstorm 
business ideas for drivers to use their waiting time productively. There appears to be an industry standard for specific actions, and it is difficult to determine who is correct and who is not. For example, who is to blame if a booking is canceled due to the COVID-19? Is it the customer, the SP, or the platform? Because it appears that each party is blaming the other, it is time to create guidelines for such situations.

Few industries have seen such gigantic job losses and income drops. As a result, some mechanisms are required to protect SPs' earnings. Social distancing is also an essential issue in sharing services-perhaps it is time to think of designs that can protect drivers and passengers from the viral transmission. Sharing platforms have come under fire from a variety of sources. The larger platforms will almost certainly take corrective actions to persuade their critics that they are invested in the wellbeing of their stakeholders. They have, at present, taken some steps in this direction, such as developing long-term and short-term strategies to deal with the COVID-19 crisis and the aftermath.

\section{Conclusion}

The study aims to identify the effects of the COVID-19 pandemic have on regulatory bodies of SE firms (Uber, Lyft, Airbnb, Vrbo and UberEats), their SPs (Uber drivers and Airbnb hosts) and people worldwide who act as SRs. Also, this study tries to find out the dealing approaches to combat the consequences of COVID-19 pandemic impacts by the regulatory bodies of SE firms, their associated SPs and SRs. The results achieved from CA demonstrated that COVID-19 significantly impacted job sectors, increased health risk, safety, and anxiety, and reduced income for the sectors associated with SE firms, SPs and SRs worldwide. Regulatory bodies related to SE platforms are facing tremendous difficulties in operating their activities, frequently changing guidelines to support SPs by financial assistance and SRs by standard services during the pandemic. Also, SE firms were impacted by the unexpected attitudes shown by the SRs in the form of not respecting the agreement with SPs, canceled bookings and demanding a full refund, and violating social isolation and health guidelines protocols during the pandemic. Several SE firms have been taken effective policies by increasing flexibility for employees to work from home, providing subsidies to support SPs and compensate the customer, making health insurance for employees and SPs, limiting services in high infected areas during the pandemic and seeking financial help from the state government to overcome the impacts of COVID-19 pandemic. The approaches taken by the regulatory bodies of SE firms will reduce the job risks, overcome the monitory loss, investment concern, compensate SRs with little or low income, help reduce mental stress and anxiety, and challenges to manage SE firms during any kind of pandemic. As the SE firms are providing tremendous support worldwide by contributing to the national economy, the central government of each country needs to make effective policies to support this sector during any pandemic through finance and subsidies.

Acknowledgements We want to express our heartiest gratitude to the experts of Dynamic Institution of Geospatial Observation Network DIGON (http://digonresearch.org/), a research consultancy firm for proofreading and assistance to publish the manuscript.

Funding No funding has been received for this work.

Data availability The data utilized in this study has been acquired from freely available sources.

\section{Declarations}

Conflict of interest The authors declare that they have no known competing financial interests or personal relationships that could have influenced the work reported in this paper.

\section{References}

1. Yeo, S. F., Tan, C. L., Teo, S. L., \& Tan, K. H. (2021). The role of food apps servitization on repurchase intention: A study of FoodPanda. International Journal of Production Economics, 234, 108063.

2. Zhou, B., Liu, T., Ryan, C., Wang, L.-E., \& Zhang, D. (2020). The satisfaction of tourists using bicycle sharing: A structural equation model-the case of Hangzhou, China. Journal of Sustainable Tourism, 28, 1063-1082.

3. Cowling, M., Brown, R., \& Rocha, A. (2020). <? covid19?> Did you save some cash for a rainy COVID-19 day? The crisis and SMEs. International Small Business Journal, 38, 593-604.

4. Lee, S. M., \& Trimi, S. (2021). Convergence innovation in the digital age and in the COVID-19 pandemic crisis. Journal of Business Research, 123, 14-22.

5. de Sousa Jabbour, A. B. L., Jabbour, C. J. C., Hingley, M., Vilalta-Perdomo, E. L., Ramsden, G., \& Twigg, D. (2020). Sustainability of supply chains in the wake of the coronavirus (COVID-19/SARS-CoV-2) pandemic: Lessons and trends. Modern Supply Chain Research and Applications.

6. Hossain, M. (2021). The effect of the Covid-19 on sharing economy activities. Journal of Cleaner Production, 280, 124782.

7. Kumar, P., Singh, S. K., Pereira, V., \& Leonidou, E. (2020). Cause-related marketing and service innovation in emerging country healthcare. International Marketing Review.

8. Mont, O., Palgan, Y. V., Bradley, K., \& Zvolska, L. (2020). A decade of the sharing economy: Concepts, users, business and governance perspectives. Journal of Cleaner Production, 122215.

9. Brammer, S., Branicki, L., \& Linnenluecke, M. K. (2020). COVID-19, societalization, and the future of business in society. Academy of Management Perspectives, 34, 493-507.

10. Chesbrough, H. (2020). To recover faster from Covid-19, open up: Managerial implications from an open innovation perspective. Industrial Marketing Management, 88, 410-413. 
11. Teubner, T., \& Flath, C. M. (2019). Privacy in the sharing economy. Journal of the Association for Information Systems, 20, 2.

12. Cui, R., Li, J., \& Zhang, D. J. (2020). Reducing discrimination with reviews in the sharing economy: Evidence from field experiments on Airbnb. Management Science, 66, 1071-1094.

13. Filippas, A., Horton, J. J., \& Zeckhauser, R. J. (2020). Owning, using, and renting: Some simple economics of the "sharing economy." Management Science, 66, 4152-4172.

14. Hossain, M. (2020). Sharing economy: A comprehensive literature review. International Journal of Hospitality Management, $87,102470$.

15. Mody, M., Suess, C., \& Lehto, X. (2019). Using segmentation to compete in the age of the sharing economy: Testing a core-periphery framework. International Journal of Hospitality Management, 78, 199-213.

16. Cheng, X., Fu, S., Sun, J., Bilgihan, A., \& Okumus, F. (2019). An investigation on online reviews in sharing economy driven hospitality platforms: A viewpoint of trust. Tourism Management, 71, 366-377.

17. Hagiu, A., \& Wright, J. (2019). The status of workers and platforms in the sharing economy. Journal of Economics \& Management Strategy, 28, 97-108.

18. Muduli, K. K., Luthra, S., Kumar Mangla, S., Jabbour, C. J. C., Aich, S., \& de Guimarães, J. C. F. (2020). Environmental management and the "soft side" of organisations: Discovering the most relevant behavioural factors in green supply chains. Business Strategy and the Environment, 29, 1647-1665.

19. Geissinger, A., Laurell, C., \& Sandström, C. (2020). Digital Disruption beyond Uber and Airbnb-Tracking the long tail of the sharing economy. Technological Forecasting and Social Change, 155, 119323.

20. Yang, S.-B., Lee, K., Lee, H., \& Koo, C. (2019). In Airbnb we trust: Understanding consumers' trust-attachment building mechanisms in the sharing economy. International Journal of Hospitality Management, 83, 198-209.

21. Raj, M., Sundararajan, A., \& You, C. (2020). COVID-19 and digital resilience: Evidence from Uber Eats. arXiv preprint arXiv: 2006.07204

22. Umer, H. (2021) Illusory freedom of physical platform workers: Insights from Uber Eats in Japan. The Economic and Labour Relations Review, 1035304621992466.

23. George, G., Lakhani, K. R., \& Puranam, P. (2020). What has changed? The impact of Covid pandemic on the technology and innovation management research agenda. Journal of Management Studies, 57, 1754-1758.

24. Kirk, C. P., \& Rifkin, L. S. (2020). I'll trade you diamonds for toilet paper: Consumer reacting, coping and adapting behaviors in the COVID-19 pandemic. Journal of Business Research, 117, 124-131.

25. Mont, O., Curtis, S. K., \& Palgan, Y. V. (2021). Organisational Response Strategies to COVID-19 in the Sharing Economy. Sustainable Production and Consumption, 28, 52-70.

26. Amankwah-Amoah, J. (2020). Stepping up and stepping out of COVID-19: New challenges for environmental sustainability policies in the global airline industry. Journal of Cleaner Production, 271, 123000.

27. Curtis, S. K., \& Mont, O. (2020). Sharing economy business models for sustainability. Journal of Cleaner Production, 266, 121519 .
28. Gyódi, K. (2019). Airbnb in European cities: Business as usual or true sharing economy? Journal of Cleaner Production, 221, 536-551.

29. Wang, D., \& Nicolau, J. L. (2017). Price determinants of sharing economy based accommodation rental: A study of listings from 33 cities on Airbnb.com. International Journal of Hospitality Management, 62, 120-131.

30. Cheng, M., Chen, G., Wiedmann, T., Hadjikakou, M., Xu, L., \& Wang, Y. (2020). The sharing economy and sustainabilityassessing Airbnb's direct, indirect and induced carbon footprint in Sydney. Journal of Sustainable Tourism, 28, 1083-1099.

31. Mauri, A. G., Minazzi, R., Nieto-García, M., \& Viglia, G. (2018). Humanize your business. The role of personal reputation in the sharing economy. International Journal of Hospitality Management, 73, 36-43.

32. Krouk, R., \& Almeida, F. (2021). Exploring the impact of COVID-19 in the sustainability of Airbnb business model. arXiv preprint arXiv:2101.00281

33. Kim, B., Azzaro-Pantel, C., Pietrzak-David, M., \& Maussion, P. (2019). Life cycle assessment for a solar energy system based on reuse components for developing countries. Journal of Cleaner Production, 208, 1459-1468.

34. Zheng, Y., Goh, E., \& Wen, J. (2020). The effects of misleading media reports about COVID-19 on Chinese tourists' mental health: A perspective article. Anatolia, 31, 337-340.

35. Amit, S., Barua, L., \& Kafy, A.-A. (2021). A perception-based study to explore COVID-19 pandemic stress and its factors in Bangladesh. Diabetes \& Metabolic Syndrome: Clinical Research \& Reviews.

36. Johnston, M. P. (2017). Secondary data analysis: A method of which the time has come. Qualitative and Quantitative Methods in Libraries, 3, 619-626.

37. Zhao, E. Y., \& Wry, T. (2016). Not all inequality is equal: Deconstructing the societal logic of patriarchy to understand microfinance lending to women. Academy of Management Journal, 59, 1994-2020.

38. Zenker, S., \& Kock, F. (2020). The coronavirus pandemic-A critical discussion of a tourism research agenda. Tourism Management, 81, 1041.

39. Xie, K. L., Zhang, Z., \& Zhang, Z. (2014). The business value of online consumer reviews and management response to hotel performance. International Journal of Hospitality Management, $43,1-12$.

40. Soldatenko, D., \& Backer, E. (2019). A content analysis of crosscultural motivational studies in tourism relating to nationalities. Journal of Hospitality and Tourism Management, 38, 122-139.

41. Neuendorf, K. A., \& Kumar, A. (2015). Content analysis. The International Encyclopedia of Political Communication, 1-10

42. Vaismoradi, M., Jones, J., Turunen, H., \& Snelgrove, S. (2016). Theme development in qualitative content analysis and thematic analysis.

43. Li-Ying, J., \& Nell, P. (2020). Navigating opportunities for innovation and entrepreneurship under COVID-19. California Management Review.

44. Rahman, S., Amit, S., \& Kafy, A.-A. (2021). Gender disparity in telehealth usage in Bangladesh during COVID-19. SSM-Mental Health, 100054

Publisher's Note Springer Nature remains neutral with regard to jurisdictional claims in published maps and institutional affiliations. 